\title{
The impracticality of a universal drought definition
}

Article

Accepted Version

Lloyd-Hughes, B. (2013) The impracticality of a universal drought definition. Theoretical and Applied Climatology, 117 (3-4). pp. 607-611. ISSN 1434-4483 doi:

https://doi.org/10.1007/s00704-013-1025-7 Available at https://centaur.reading.ac.uk/35085/

It is advisable to refer to the publisher's version if you intend to cite from the work. See Guidance on citing.

To link to this article DOI: http://dx.doi.org/10.1007/s00704-013-1025-7

Publisher: Springer

All outputs in CentAUR are protected by Intellectual Property Rights law, including copyright law. Copyright and IPR is retained by the creators or other copyright holders. Terms and conditions for use of this material are defined in the End User Agreement.

\section{www.reading.ac.uk/centaur}

\section{CentAUR}

Central Archive at the University of Reading

Reading's research outputs online 


\title{
The impracticality of a universal drought definition
}

\author{
Benjamin Lloyd-Hughes
}

Walker Institute for climate system research, Department of Meteorology, University of Reading, UK.

\section{Revision 2}

November 4, 2013

Corresponding author address: Benjamin Lloyd-Hughes, Walker Institute for climate system research, Department of Meteorology, University of Reading, RG6 6AR, UK. Email: b.lloydhughes@reading.ac.uk 


\section{Abstract}

This paper demonstrates the impracticality of a comprehensive mathematical definition of the term 'drought' which formalises the general qualitative definition that drought is 'a deficit of water relative to normal conditions'. Starting from the local water balance, it is shown that a universal description of drought requires reference to water supply, demand and management. The influence of human intervention through water management is shown to be intrinsic to the definition of drought in the universal sense and can only be eliminated in the case of purely meteorological drought. The state of 'drought' is shown to be predicated on the existence of climatological norms for a multitude of process specific terms. In general these norms are either difficult to obtain or even non-existent in the non-stationary context of climate change. Such climatological considerations, in conjunction with the difficulty of quantifying human influence, lead to the conclusion that we cannot reasonably expect the existence of any workable generalised objective definition of drought.

\section{Introduction}

Drought is one of the most deadly natural hazards, and yet a universal definition of the term has proven to be elusive. The Oxford English Dictionary (2011) defines drought as:

1. The condition or quality of being dry; dryness, aridity, lack of moisture.

2. Dryness of the weather or climate; lack of rain.

Unfortunately, the conflation of dryness with aridity and weather with climate serves more to confuse than illuminate. The World Meteorological 
Organization (1992) glossary provides a slightly better definition of drought as a:

1. Prolonged absence or marked deficiency of precipitation.

2. Period of abnormally dry weather sufficiently prolonged for the lack of precipitation to cause a serious hydrological imbalance.

However, to focus solely on precipitation is to neglect the importance of evaporation and transpiration as moisture sinks which reduce the amount of water available for use. The definition also ignores the importance of lateral inflows (stream and ground water flows) into a region that can serve as important water sources in addition to the local precipitation. Further, the definition makes no reference to the timing of the precipitation deficits, a factor which is crucial in the determination of many drought impacts. Sheffield and Wood (2011) succeed in defining drought both accurately and succinctly as 'a deficit of water relative to normal conditions'. This echoes Palmer (1965) that drought:

Is an interval of time, generally of the order of months or years in duration, during which the actual moisture supply at a given place rather consistently falls short of the climatically expected or climatically appropriate moisture supply.

This captures the two aspects of water deficiency identified by Mawdsley et al. (1994) as essential when assessing drought severity: i) the duration of the dry period and ii) the region or location to be considered.

The subject of drought definition is not an academic pursuit. Smakhtin and Schipper (2008) provide a discussion of the semantics and perceptions of drought which concludes that the terminology used in the field of disaster 
research and management may significantly affect relevant policies and actions. Thus, drought definition has important consequences far beyond the applied statistics of theoretical climatology.

Numerous attempts have been made to describe drought numerically through the development of drought indices. The difficulty and importance of defining drought objectively is manifest in the large number of indices (> 100) that have been proposed for use in drought monitoring. Particular indices have typically been developed on an ad hoc basis to emphasise some particular drought impact, be it meteorological, hydrological, agricultural or socio-economic (to borrow the classification of Wilhite and Glantz (1985)). Unfortunately, rather than clarify the definition, the plethora of indices creates further confusion and brings into question the very feasibility of defining drought in a quantitative fashion outside of specific impacts (see e.g. Heim Jr. (2002), van Lanen et al. (2009), White and Walcott (2009)). The perception of drought severity through its impacts leads Mawdsley et al. (1994) to suggest that drought (specifically hydrological drought but true of drought in general) may be viewed in three ways:

1. from a scientist's viewpoint, drought severity should be assessed using indicators which are neither subjective nor unduly influenced by water companies' operational strategies. Whenever possible, hydrological data for this type of assessment should ideally be natural or naturalised to account for any artificial influences;

2. those involved in water supply may prefer to analyse derived data, such as abstracted quantities or regulation releases from reservoirs, despite the influence of the operating policy on these data;

3. individuals affected by the drought may find an analysis based upon the 
impact on their social and economic activity (e.g. gardening, fishing, agricultural production) more appropriate.

The conclusion is, that because of these disparate views of droughts, there is no single method of assessing and describing drought severity which will be suitable for all circumstances and users. The aim of this paper is to formalise this conjecture and to conclusively demonstrate the impracticality of a universal drought definition. Analysis of the resultant formalism leads to some philosophical reflection on the utility of 'non-universal' drought indices.

\section{Local water balance}

Water shortages are experienced locally. It is the aggregate negative effect of local water shortages summed over time across a larger geographic domain that lead to the emergence of socio-economically important 'droughts'. The fundamental quantity of interest is the moisture budget evaluated over a finite time $\tau=t_{2}-t_{1}$ where $t_{1}$ and $t_{2}$ mark the beginning and end of the accounting period at location $s$ :

$$
\begin{aligned}
{\left[\Delta Q_{\text {store }}\left(s, t=t_{2}\right)\right]_{\tau}=} & \int_{t_{1}}^{t_{2}} Q_{\text {source }}(s, t) d t \\
& -\int_{t_{1}}^{t_{2}} Q_{\text {sink }}(s, t) d t
\end{aligned}
$$

where $\Delta Q_{\text {store }}$ is the change in amount of water stored locally, $Q_{\text {source }}(s, t)$ is water arriving, and $Q_{\operatorname{sink}}(s, t)$ is water leaving. $\tau$ is usually fixed at some convenient measuring duration e.g. a day, month, or year. Each component of (1) represents an aggregate of biogeophysical processes. The precise mix of processes will vary by location, time of year, and the antecedent conditions. In general, the source

$$
Q_{\text {source }}(s, t)=P+C+S_{\text {in }}+A_{\text {in }}+W_{\text {in }}+B_{\text {in }}+H_{\text {in }}
$$


where all quantities are space and time dependent and $P$ is precipitation (measured at ground level), $C$ is direct condensation, $S_{i n}$ is surface water inflow, $A_{i n}$ is aquifer inflow (soil moisture and groundwater), $W_{i n}$ is water artificially diverted in from outside of the locality (e.g. by pipe or tanker), $B_{i n}$ represents a generic biological moisture influx and $H_{\text {in }}$ is a generic input term with accounts for water created through human activity (e.g. through industrial activity). The sink

$$
Q_{\text {sink }}(s, t)=E+T+S_{\text {out }}+A_{\text {out }}+W_{\text {out }}+B_{\text {out }}+H_{\text {out }}
$$

where $E$ is evaporation from the surface, $T$ is transpiration, $S_{\text {out }}$ is surface water outflow, $A_{\text {out }}$ is aquifer outflow, $W_{\text {out }}$ is water artificially diverted out of the locality, $B_{\text {out }}$ is the biological outflux, and $H_{\text {out }}$ is a generic loss term which accounts for water lost through human activity (e.g. through industrial activity). It should be noted that there is no term for evaporation from vegetation (canopy interception) since this effect is accounted for in the measurement of precipitation at ground level. The store

$$
Q_{\text {store }}(s, t)=S_{s}+G_{s}+B_{s}+H_{s}
$$

where $S_{s}$ is surface storage (including snow/ice), $G_{s}$ is groundwater storage (including permafrost), $B_{s}$ is biological storage and $H_{s}$ is the recoverable part of $H_{\text {out }}$ which is not transported from the location.

\section{A universal drought index}

Whilst $\left[\Delta Q_{\text {store }}\right]_{\tau}<0$ represents a reduction in available water and constitutes a necessary condition, it is insufficient to define the concept of drought. It is quite normal in many parts of the world for moisture demand to far outstrip supply for large parts of the year. On short enough timescales $(\tau<1$ 
hour) this condition becomes the norm since nowhere on earth does it rain continuously. During these periods demand is met through drawing down on the reserves held in $Q_{\text {store. }}$. It is important to make a clear distinction between the component terms in the water balance and the water-requiring processes that shuffle moisture between the source, sink and storage terms e.g. cooling, drinking, photosynthesis etc., since it is through the interruption of one or more of these processes that drought impacts become manifest. Water-requiring processes define the demand for moisture. In reality, not all of $Q_{\text {store }}$ will be physically accessible, nor of sufficient quality, for each of the water-requiring processes in operation at location $s$ at time $t$. Labelling the water requirements of the individual processes as $W R_{i}$ each will see an effective reserve

$$
\left[Q_{\text {res }}\right]_{i}=f_{i}\left(Q_{\text {store }}, s, t\right)
$$

where $f_{i}$ represents a space and time dependent efficiency function that controls the fraction of each of the components of $Q_{\text {store }}$ available to satisfy $W R_{i}$ at location $s$ at time $t$. The components of $Q_{\text {store }}$ are typically themselves composites (e.g. $S_{s}$ can be decomposed into surface water (lake, reservoir), soil moisture, snow cover, etc.) and these should be individually weighted in the construction of $f_{i}$.

Denoting the climatologically expected value of (5) at location $x$ at time $t$ in the year as $\left\langle\left[Q_{\text {res }}\right]_{i}\right\rangle$ a process specific instantaneous drought $\left(D(s, t)_{i}\right)$ is defined when

$$
D(s, t)_{i}=W R(s, t)_{i}-\left\langle\left[Q_{r e s}\right]_{i}\right\rangle<0
$$

in which it is implicitly assumed that the process under consideration is in long term equilibrium with the local climate. It is this assumption that marks the distinction between drought and water scarcity (see e.g. European Commission (2007) for a discussion of the concept of water scarcity). 
Real world droughts become manifest in multiple processes and have spatial extent and duration. Hence, it is natural to consider the space-time integral of the sum of the $j \leq i$ processes where $D(s, t)_{i}<0$

$$
D(s, t)=\sum_{j} D(s, t)_{j}
$$

in the local region $R$ around $s$ from some time $\tau$ before $t$

$$
\overline{D(s, t)}_{\{\tau, R\}}=\int_{t-\tau}^{t} \int_{R} D(s, t) d t d S
$$

where $R$ defines the region, and, for convenience, the time average is taken over the same interval $\tau$ used in the water balance equation (1). Equation (8) defines the concept of an extended generalised drought at a location $s$ at a time $t$ parameterized by a duration $\tau$ and spatial extent $R$. If $\tau$ and $R$ are kept small, relative to the space-time scales that control the water balance (1) (see e.g. Figure 2.6 of Tallaksen and Van Lanen (2004) which suggests $R \approx 1 \mathrm{~km}^{2}, \tau \approx 1$ day) then $\overline{D(s, t)}_{\{\tau, R\}}$ provides a basic unit of drought which, when further aggregated across space and time, describes drought in a very general way.

\section{Discussion}

\subsection{Practical considerations}

The instantaneous droughts defined by (6) formalise the qualitative statement that drought is defined as 'a deficit of water relative to normal conditions'. Specifically, instantaneous droughts are:

1. Process specific.

2. Local in space. 
3. Local to the time of year.

4. Predicated on the existence of the climatological norm of a process specific reservoir term.

(It should be noted that reservoir terms are irrelevant in the case of purely meteorological drought in which case the existence of a climatological norm for precipitation is required. This can be seen from (5) which reduces to $\left[Q_{\text {res }}\right]_{i}=f_{i}\left(Q_{\text {store }}, s, t\right)=S_{s}$ where $S_{s}$ can be considered as the rain gauge.)

The deficits are measured in absolute terms, which, when aggregated through (7) and (8) yield a mathematical entity $\overline{D(s, t)}_{\{\tau, R\}}$ which captures the 'real world' sense that droughts impact multiple sectors across extended space and time scales. Thus, starting from the fundamentals of the local water balance, it is possible to satisfy our objective of providing a robust mathematical definition of the term 'drought' that formalises the most general qualitative definitions.

However, consideration of this general formulation reveals two major problems which preclude the practical application of this 'universal' description of drought:

\section{Problem 1}

A comprehensive description of drought requires reference to water supply, demand and management. Aside from the rare occasions when water demand is met directly from precipitation or condensation, all water-requiring processes are dependent upon storage. Since the effective reservoir terms (5) for each process are drawn from one or more of the common stores (4), the number and magnitude of the instantaneous terms in $\sum_{j} D(s, t)_{j}$ depend upon the priorities employed when choosing the order in 
which the water-requiring processes are satisfied over the course of the averaging period $\tau$. Thus, in general, it is impossible to consider drought in isolation from water management practices employed. As the timescales increase and/or reliance on direct supply from rainfall decreases, these management decisions become increasingly non-local and difficult to quantify. This poses a serious practical problem for the evaluation of (8).

\section{Problem 2}

The sum $\sum_{j} D(s, t)_{j}$ relies upon knowing all, or at least for a rough approximation, the dominant $D(s, t)_{j}$. However, practical constraints severely hamper the collation of sufficient data to compute the climatological expectation for the reservoir $\left\langle\left[Q_{r e s}\right]_{i}\right\rangle$. In many cases, e.g. for non-stationary process, the norm may be non-existent. This means that (6) is frequently undefined and thus (7) and (8) are not computable. For example, considering the simplest case where $\left\langle\left[Q_{\text {res }}\right]_{i}\right\rangle$ is purely rainfed, Figure 1 provides global maps of (a) the change in precipitation and (b) the statistical significance of changes to the empirical cumulative distribution function (ecdf) of precipitation between the periods $1901-1955$ and $1956-2010$. It is evident that non-stationarity in $\left\langle\left[Q_{r e s}\right]_{i}\right\rangle$ is more common than not. This poses serious problems not just for drought definition but also for the assessment of operational risk for the typical anthropogenic hydrosystem. These by construction are designed in order to fulfil their purpose (hydropower production, crop production, etc.), at a given yield, with respect to some 
observed hydroclimate conditions over a given period in the past (a type of crop is chosen with reference to the local climate conditions, a run-of-the-river hydropower scheme is designed with reference to past observed streamflow conditions, etc.).

(a)

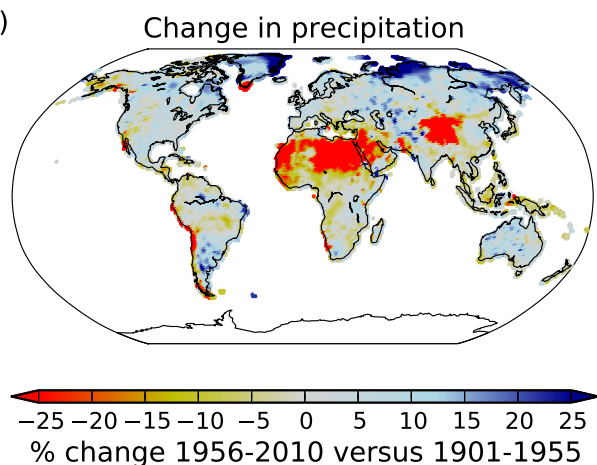

(b)

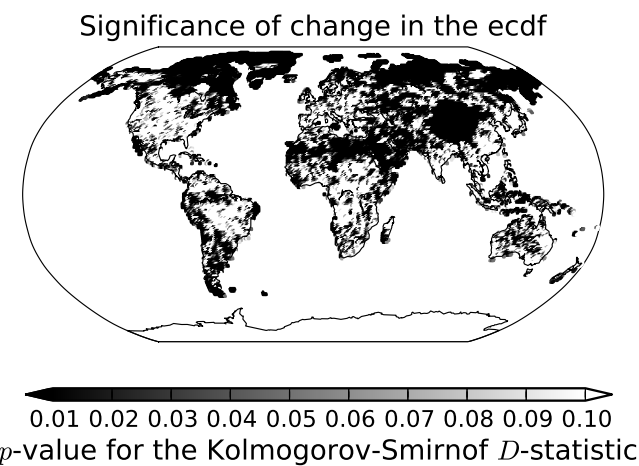

Figure 1: Global maps of (a) the change in precipitation and (b) the statistical significance of changes to the empirical cumulative distribution function (ecdf) of precipitation between the periods $1901-1955$ and $1956-2010$. The precipitation data are from the Global Precipitation Climatology Centre Full Data Reanalysis (V.6 1901-2010) gridded precipitation data at $1^{o}$ spatial resolution.

\subsection{Philosophical reflection on the utility of non-universal drought indices}

The typical response to the the practical problems described Section 4.1 is the application of one or more reductionist strategies which concentrate on various subsets of $D(s, t)_{i}$ e.g. vegetative health, or to the process components of the water balance e.g. precipitation. Such strategies have led to a 
profusion of impact specific, time specific, location specific drought indices. It is obvious from the formulation of (6) that there can be at least as many types of drought as there are processes requiring water. This number is increased through the introduction of abstract indices, e.g. the Standardised Precipitation Index, that attempt to proxy drought impacts across a range of processes. There is nothing wrong per se with these descriptions within the narrow confines of their particular definitions and they are undoubtedly useful to a range of practitioners. However, it is clear from the general definition of drought provided here, that care needs to be taken when using a particular index as a proxy for drought in the broader sense. Numerous review articles (e.g. Heim Jr. (2002), Smakhtin and Hughes (2004), Morid et al. (2006), White and Walcott (2009)) have sought to compare and contrast the abilities of various indices to describe various drought impacts. As is to be expected, the consensus is that no single index is sufficient to characterise the peril. This motivates the subjective combination of drought indicators into products, such as the United States Drought Monitor (Svoboda et al. 2002), that attempt to assess the 'total environmental moisture status' Steila (1987) or the 'basket of indicators' suggested by Mawdsley et al. (1994) which returns the discussion to $\overline{D(s, t)}_{\{\tau, R\}}$ and the inherent impracticality of the universal approach.

\section{Conclusion}

It has been shown that for most practical purposes 'drought' in the 'universal' sense is unquantifiable. In general universal drought cannot be defined without knowledge of the climatologically expected values for the availability of stored water for a given need. Or in the case of meteorological drought, 
where reservoir terms are irrelevant, knowledge of the normal precipitation. In many cases these climatologies are not known, and in some cases they are unknowable. Further, in all but the purest of meteorological droughts, since most needs are met from extractions from a common store, it is impossible to consider drought in isolation from water management practices employed. The development of a general mathematical description of drought has shown, unsurprisingly, that a universal description of drought requires reference to water supply, demand and management. Consideration of how the generalised concept of drought emerges from the aggregation of process specific instantaneous droughts reveals the origin of the multitude of drought indices that populate the drought related literature. The existence, however impractical, of a universal measure for drought raises the question of the relevance of specialised drought indices to the concept of 'drought' beyond the narrow scope of their definition. The application of non-universal drought indices is a practical necessity, however caution must be applied to avoid an implied relevance to drought in the broader sense, which may go beyond what is justified. This is not to say that drought cannot be discussed meaningfully, only that the discourse maybe better suited to aggregate indicators and subjective discussion than by summary statistics of simplistic drought indices alone.

\section{Acknowledgment}

The author thanks Deloitte for supporting the Deloitte-Walker Institute Research Fellowship at the University of Reading. 


\section{References}

European Commission. Second interim report on water scarcity and droughts. European Commission, June 2007. 93 pp.

R. R. Heim Jr. A review of twentieth-century drought indices used in the United States. Bull. Amer. Meteor. Soc., 83(8):1149-1165, 2002.

J. Mawdsley, G. Petts, and S. Walker. Assessment of drought severity. British Hydrological Society, 1994. 30 pp.

S. Morid, V. Smakhtin, and M. Moghaddasi. Comparison of seven meteorological indices for drought monitoring in Iran. Int. J. Climatol., 26(7): 971-985, 2006.

Oxford English Dictionary. Definition of drought. Oxford University Press, 2011. URL http://oxforddictionaries.com/definition/drought.

W. C. Palmer. Meteorological drought. Research Paper No.45. US Weather Bureau, Washington, D.C., 1965. 58 pp.

J. Sheffield and E. F. Wood. Drought: Past problems and future scenarios. Earthscan, 2011. 210 pp.

V. U. Smakhtin and D. A. Hughes. Review, Automated Estimation and Analyses of Drought Indices in South Asia. Number Working Paper No. 83 - Drought Series Paper No. 1. IWMI, 2004. 24 pp.

V. U. Smakhtin and E. L. F. Schipper. Droughts: The impact of semantics and perceptions. Water Policy, 10(2):131-143, 2008.

D. Steila. The encyclopedia of climatology, chapter Drought, pages 388-395. van Nostrand Reinhold, 1987. pp 1002. 
M. Svoboda, D. LeComte, M. Hayes, R. Heim, K. Gleason, J. Angel, B. Rippey, R. Tinker, M. Palecki, D. Stooksbury, D. Miskus, and S. Stephens. The Drought Monitor. Bull. Amer. Meteor. Soc., 83(8): 1181-1190, 2002.

L.M. Tallaksen and H.A.J. Van Lanen. Hydrological Drought: Processes And Estimation Methods For Streamflow And Groundwater. Developments in Water Science. Elsevier, 2004. ISBN 9780444517678. 579 pp.

H. A. J. van Lanen, Zbigniew W. Kundzewicz, Lena M. Tallaksen, Hege Hisdal, Miriam Fendeková, and Christel Prudhomme. Indices for different types of droughts and floods at different scales. WATCH Technical Report No. 11, 2009. 20 pp.

D. H. White and J. J. Walcott. The role of seasonal indices in monitoring and assessing agricultural and other droughts: a review. Crop and Pasture Science, 60:599-616, 2009.

D. A. Wilhite and M. H. Glantz. Understanding the drought phenomenon: The role of definitions. Water Int., 10:3:111-120, 1985.

World Meteorological Organization. International meteorological vocabulary. 2nd ed. World Meteorological Organization (WMO), Geneva, 1992. Publication no. 182, $784 \mathrm{pp}$. 